\title{
Factors Associated with Suboptimal Adherence to Hypertensive Medications Among Syrian Refugees - Cross-Sectional Study at the Zaatari Camp, Jordan
}

\author{
Sara Abu Khudair (D) \\ Yousef S Khader (D) ${ }^{2}$ \\ Hana Morrissey ${ }^{3}$ \\ Ziad El-Khatib ${ }^{4}$ \\ Janos Sandor'
}

'Department of Public Health and Epidemiology, Faculty of Medicine, University of Debrecen, Debrecen, Hungary; ${ }^{2}$ Department of Community Medicine, Public Health and Family Medicine, Jordan University of Science and Technology, Irbid, Jordan; ${ }^{3}$ Faculty of Science and Engineering, School of Pharmacy, University of Wolverhampton, Wolverhampton, UK; ${ }^{4}$ Department of Global Public Health, Karolinska Institute, Stockholm, Sweden
Correspondence: Sara Abu Khudair Email Sara.A.Khudair@gmail.com
Objective: This study aimed to assess the level of medication adherence and associated factors among Syrian refugees with hypertension in Jordan.

Methods: This cross-sectional study included 180 randomly selected Syrian refugees diagnosed with hypertension residing in Zaatari camp, Jordan. The Adherence to Refills and Medications Scale (ARMS) was used to assess adherence to antihypertensive medications. Additional data were collected on sociodemographics, therapy-related factors, patients' behaviors and knowledge of hypertension disease and therapy, and health system-related factors. Multivariate linear regression was used to assess the association between adherence scores and other variables.

Results: The mean (SD) of ARMS scores was 15.7 (2.9). Based on ARMS scores, $22.8 \%$ of patients were adherents and $77.2 \%$ were non-adherents. Multivariate analysis showed that newly initiated therapy ( $\leq 2$ years) and illiteracy were both strong predictors of lower adherence with $\mathrm{p}<0.001$ and $\mathrm{p}=0.012$, respectively. Other variables that were significantly associated with lower adherence included discontinuation of antihypertensive medications due to side effects $(p=0.032)$, reporting irregular availability of free antihypertensive medications dispensed by non-governmental organizations (NGOs) ( $p=0.024)$, and dissatisfaction with health services $(p=0.022)$.

Conclusion: Suboptimal adherence to antihypertensive medications remains a substantial unmet need among Syrian refugees with hypertension. As illiteracy appears to have a negative impact on adherence levels, educational interventions that promote medication adherence and favorable health behaviors through auditory and visual aids are needed to better reach and engage people with limited literacy skills. Strengthening the pharmaceutical supply chain at various levels is strongly recommended to respond quickly to changes in demand and prevent an indirect negative impact on adherence levels.

Keywords: Syrian refugees, medication adherence, hypertension, illiteracy, medications availability, Zaatari camp

\section{Introduction}

Since the start of the Syrian conflict in 2011, more than 6.6 million Syrians have fled to nearby and abroad destinations. ${ }^{1}$ Jordan, as a neighboring country, has welcomed more than one million Syrian refugees, representing almost $15 \%$ of the population. Of those, around 660,000 are registered with the United Nations High Commissioner for Refugees (UNHCR) and are eligible for health services at Jordanian Ministry of 
Health facilities with the system of co-payment as uninsured Jordanians ( $80 \%$ of the cost). ${ }^{2,3}$ Alternatively, Syrian camp refugees and vulnerable Syrian urban refugees can access free primary health care services, medicines, and tests at facilities supported by the UNHCR health partners, which include those run by Non-Governmental Organizations (NGOs). ${ }^{3,4}$ In case of unavailability of free medications from NGOs' health facilities, patients are left with the option of purchasing from the local market or requesting from others. ${ }^{5}$

Health care utilization by the Syrian refugee community in Jordan continues to be hampered by several issues that have obvious implications in determining one's health behavioral patterns - notably, the financial constraints faced by this community, the irregular availability of medicines for chronic diseases, and limited funding available to humanitarian organizations. ${ }^{5,6}$ The reported high caseload of Non-communicable diseases (NCDs) among this community has raised concerns over the extent to which patients are taking their medications as prescribed, commonly referred to as "medication adherence". ${ }^{6,7}$ Assessing the level and factors associated with this behavior is essential for developing tailored interventions and supporting patient-centered care. The consequences of untreated or inadequately treated hypertension include worsening of the condition, avoidable deaths, and higher hospitalization rates and costs. ${ }^{7}$ Among the Syrian refugee population, financial constraints and perceptions of hypertension disease and treatment were frequently reported as important determining factors of adherence. ${ }^{8,9}$ Other studies reported the presence of adaptive approaches to limited health access with a potential negative impact on adherence levels. For instance, some may share their prescribed medications by requesting/borrowing from, giving/selling to acquaintances, friends, or relatives, while others may use Complementary and Alternative Medicine (CAM) as an alternative to their prescribed medication, or even intentionally reduce the treatment dosage. ${ }^{5,10}$

Although patients' behaviors and knowledge of hypertension diseases and therapy, medication availability, financial constraints, and other reported challenges can lead to lower medication adherence in the refugee population, the extent and factors associated with antihypertensive medication adherence and how to effectively improve this behavior in this population are still not well represented in the literature. Besides, generalizing the results of adherence studies conducted among Syrian refugees in different regional host countries is rather unreliable, as each of these countries has a different model of health care delivery for this population. ${ }^{11}$ The lack of such evidence represents a missed opportunity to reduce preventable hypertension-related morbidities, mortalities, and healthcare costs. This knowledge gap also limits the applicability and effectiveness of interventions meant to mitigate this issue. Thus, we aimed to assess the level of medication adherence among Syrian refugees diagnosed with hypertension in Jordan and determine associated factors.

\section{Materials and Methods Study Setting}

Zaatari camp was established in 2012 in response to the large influx of Syrian refugees who fled to Jordan following the start of the Syrian conflict. It is considered the largest Syrian refugee camp in the world, housing nearly 80,000 Syrian refugees, $42.7 \%$ of whom are between the ages of 18 and $59 .{ }^{12}$ The camp's residents rely primarily on humanitarian aids to meet their living expenses, as employment opportunities are limited. ${ }^{13}$

\section{Study Design and Data Collection}

This cross-sectional study included a randomly selected sample of Syrian patients diagnosed with hypertension living in Zaatari camp, Jordan. The study was performed between December 2020 and January 2021. A random sample was drawn from a pre-prepared list that included phone numbers, age, gender, co-existing chronic diseases, and generic names of medications taken by a group of Syrian hypertensive patients who attended a primary health care clinic in Zaatari camp in 2018. The inclusion criteria were: (1) Syrian adult refugee (18-75 years), (2) diagnosed with hypertension as derived from the primary list and further confirmed by self-reported data, (3) treated with one or more antihypertensive medications as derived from the primary list and further confirmed by selfreported data, and (4) who confirmed their voluntary participation by verbal consent. Patients with co-existing chronic conditions were also included.

Two health care workers used a structured questionnaire to collect data by conducting phone call interviews with selected patients. Meeting patients in person was not possible due to COVID-19 nationwide lockdowns and social protection measures in Jordan. The verbal administration of the questionnaire items well-suited the previously reported high functional illiteracy among Syrian 
refugees in Jordan. ${ }^{14}$ Patients were first informed about the research objectives and their anonymity and voluntary participation. After, participants were checked for inclusion and exclusion criteria. Only those who met the inclusion criteria and provided verbal informed consent were included in the study. The study was conducted in accordance with the Declaration of Helsinki and ethical approval including verbal consent was obtained from the Institutional Review Board at Jordan University of Science and Technology (Reference No: 26/135/2020).

\section{Questionnaire}

The questionnaire was developed based on an extensive literature review, concerns raised by health workers in the camp, and anecdotal evidence reported by the camps' hypertensive patients. The questionnaire included information on sociodemographics, therapy-related factors, patients' behavior and knowledge of hypertension disease and therapy, the health care system-related factors, and the patients' adherence to antihypertensive medications using the Adherence to Refills and Medications Scale (ARMS). Patients' use of CAM was also assessed as part of their overall knowledge of hypertension therapy by asking about replacing their prescribed hypertension medications with herbal remedies. Literacy was assessed based on patients' self-reported ability to read and write. ${ }^{15}$ Data on coexisting chronic conditions were not included in the analysis as the pre-prepared list with corresponding chronic diseases was from 2018 and using it might miss additional variances in medical diagnosis. While the sole use of selfreported comorbidities will require a high degree of patient knowledge about current health status, and their importance warrants verification of their accuracy by using more objective measures such as relatively recent medical records. To ensure a high level of engagement in responding to the adherence scale and to avoid boredom, socio-demographic data were placed at the end of the questionnaire and asked last. The questionnaire was initially tested on 10 Syrian hypertensive patients who were not included in the final analysis.

ARMS consists of 12 questions scored on a Likert scale ranging from "none of the time" to "all of the time", helping in screening nuances in respondents' answers that might be overlooked with binary "yes/no" answers. ${ }^{16,17}$ The range of possible scores is 12 to 48 , with lower scores indicating better adherence. ARMS exhibited a high internal consistency (Cronbach's $\alpha=0.814$ ) when used in patients with chronic diseases. Internal consistency was also high among patients with inadequate literacy skills $(\alpha=0.792)$ or marginal/adequate literacy $(\alpha=0.828) .{ }^{16}$ In this study, the Arabic version of the scale was used after obtaining permission from the developer. ARMS was previously translated into the Arabic context and used to assess adherence in Arabicspeaking patients with chronic diseases in Qatar. ${ }^{18}$

\section{Statistical Analysis}

Statistical analysis was conducted with IBM SPSS 24 (IBM Corp. Released 2016. IBM SPSS Statistics for Windows, Version 24.0. Armonk, NY: IBM Corp.). Descriptive analysis was performed for continuous variables as mean and standard deviation, while categorical variables were presented as frequencies and percentages. ARMS scores were categorized into: "adherent" with scores of 12 or 13 and "non-adherent" with scores of 14 to $48 .{ }^{16}$ Intergroup differences in ARMS scores were assessed with either the independent $t$-test or ANOVA, as appropriate. Levene's test was used to assess the homogeneity of variances.

For multivariate analysis, multiple linear regression was used to assess the association of different variables with ARMS scores. Variables that had p-values of less than 0.25 in the bivariate analysis were included in the multivariate analysis. The normality of the residuals for the multiple regression model was checked graphically. The dependent variable for both the bivariate and multivariate analyses was ARMS scores, a continuous variable ranging from 12 to 48 , with lower scores indicating better adherence. A p-value of 0.05 or less was considered to indicate statistical significance.

Using a sample size of 180 persons for conducting a linear multiple regression analysis that includes 17 predictors, the power of the study exceeded $80 \%$ to detect a small effect size $(<0.3)$ at a level of significance of 0.05 . The power of the study was calculated using $\mathrm{G}^{*}$ power 3.0.10 for Windows.

\section{Results}

\section{The Socio-Demographic and Therapy-Related Factors}

Of the 180 patients included in the study, about half were female (53.9\%) and between 18 and 55 years of age $(48.3 \%)$. The majority were married $(87.2 \%)$, unemployed $(85.6 \%)$, and non-smokers (73.9\%). Almost one-third (30.0\%) were illiterate. Most patients were taking one antihypertensive medication per day (68.9\%) and $80.6 \%$ had been treated for hypertension for more than two years (Table 1). 
Table I The Socio-Demographics and Therapy-Related Factors with Intergroup Differences in ARMS Mean Scores $(n=180)$

\begin{tabular}{|c|c|c|c|}
\hline Variable & n (\%) & $\begin{array}{c}\text { ARMS Mean } \\
\quad( \pm S D)\end{array}$ & P-value \\
\hline $\begin{array}{l}\text { Age } \\
\qquad \begin{array}{l}18-55 \text { years } \\
56-75 \text { years }\end{array}\end{array}$ & $\begin{array}{l}87(48.3 \%) \\
93(51.7 \%)\end{array}$ & $\begin{array}{l}16.0(3.3) \\
15.5(2.5)\end{array}$ & 0.242 \\
\hline $\begin{array}{l}\text { Gender } \\
\text { Male } \\
\text { Female }\end{array}$ & $\begin{array}{l}83(46.1 \%) \\
97(53.9 \%)\end{array}$ & $\begin{array}{l}15.7(3.0) \\
15.7(2.9)\end{array}$ & 0.921 \\
\hline $\begin{array}{l}\text { Marital status } \\
\text { Single } \\
\text { Married } \\
\text { Divorced/ Widowed }\end{array}$ & $\begin{array}{c}2(1.1 \%) \\
157(87.2 \%) \\
21(11.7 \%)\end{array}$ & $\begin{array}{c}14(1.4) \\
15.8(3.0) \\
15.5(2.7)\end{array}$ & 0.661 \\
\hline $\begin{array}{l}\text { Literacy status } \\
\text { Literate } \\
\text { Illiterate }\end{array}$ & $\begin{array}{l}126(70 \%) \\
54(30 \%)\end{array}$ & $\begin{array}{l}15.5(2.9) \\
16.3(2.8)\end{array}$ & 0.084 \\
\hline $\begin{array}{l}\text { Employment status } \\
\text { Employed } \\
\text { Unemployed }\end{array}$ & $\begin{array}{c}26(14.4 \%) \\
154(85.6 \%)\end{array}$ & $\begin{array}{l}14.8(2.0) \\
15.9(3.0)\end{array}$ & 0.019 \\
\hline $\begin{array}{l}\text { Smoking status } \\
\text { Smoker } \\
\text { Non-smoker }\end{array}$ & $\begin{array}{l}47(26.1 \%) \\
133(73.9 \%)\end{array}$ & $\begin{array}{l}15.6(3.2) \\
15.8(2.8)\end{array}$ & 0.775 \\
\hline $\begin{array}{l}\text { HTN medication(s)/day } \\
\quad{ }^{>}\end{array}$ & $\begin{array}{c}124(68.9 \%) \\
56(31.1 \%)\end{array}$ & $\begin{array}{l}15.5(2.8) \\
16.2(3.1)\end{array}$ & 0.082 \\
\hline $\begin{array}{l}\text { HTN treatment duration } \\
>2 \text { years } \\
\leq 2 \text { years }\end{array}$ & $\begin{array}{c}145 \text { (80.6\%) } \\
35 \text { (19.4\%) }\end{array}$ & $\begin{array}{l}15.3(2.6) \\
17.4(3.6)\end{array}$ & 0.002 \\
\hline
\end{tabular}

Note: Lower ARMS scores indicate better adherence.

Abbreviations: ARMS, Adherence to Refills and Medications Scale; HTN, hypertension; SD, standard deviation.

\section{Patients' Behaviors and Knowledge of Hypertension Disease and Therapy}

The majority of patients $(90.6 \%)$ were aware of the lifethreatening conditions associated with uncontrolled high blood pressure. However, nearly one-third of participants (34.4\%) had limited knowledge about the risk of using CAM as a substitute for conventional hypertension treatment, either accepting its use as a substitute or expressing no knowledge of this matter. The issue of transportation to the dispensing pharmacy or clinic was a barrier for only a small proportion of subjects (10.6\%) and $40.6 \%$ reported their inability to pay for their antihypertensive medications if not available for free. Nearly one-fifth reported using antihypertensive medications prescribed for others when they ran out of them
(17.8\%), and a relatively similar proportion of patients reported discontinuing their antihypertensive medications due to side effects (18.9\%) (Table 2).

\section{The Health System-Related Factors}

Approximately, three-quarters of the patients reported their satisfaction with the health care services, time spent on consultations, and the delivery of lifestyle recommendations and explanations of the causes and complications of hypertension by the treating physicians (69.4-74.4\%). About 26.7\% reported an irregular availability of free antihypertensive medications dispensed by NGO's health facilities. Syrian hypertensive refugees preferred home delivery of their antihypertensive medications to improve adherence (70.6\%) and few preferred Short Message System (SMS) via mobile phone services as a reminder $(2.2 \%)$ (Table 3$)$.

\section{Adherence Rates and Associated Factors}

The mean (SD) of ARMS score was 15.7 (2.9). Based on ARMS score, $22.8 \%$ of patients were adherents and $77.2 \%$ were non-adherents. (Table 4) Bivariate and multivariate analyses were used to assess the association of different variables with adherence scores. In bivariate analysis, employment status $(\mathrm{p}=0.019)$, treatment duration $(\mathrm{p}=0.002)$, satisfaction with health care services $(\mathrm{p}=0.018)$, stopping medications due to side effects $(\mathrm{p}=0.007)$, time sufficiency of consultations $(p=0.013)$, the presence of adequate explanation by the treating physician about causes and complications of hypertension $(p=0.007)$, and the availability of free antihypertensive medications dispensed by NGOs health facilities $(p=0.001)$ were significantly associated with adherence scores (Tables 1-3).

The multiple linear regression analysis showed that having a shorter treatment duration ( $\leq 2$ years) $(\mathrm{p}<0.001)$, illiteracy $(\mathrm{p}=0.012)$, dissatisfaction with health care services $(\mathrm{p}=0.022)$, reporting an irregular availability of free antihypertensive medications ( $\mathrm{p}=0.024)$, and reporting discontinuation of medications due to side effects ( $\mathrm{p}=0.032$ ) were significantly associated with increased ARMS and therefore indicating less adherence to medications (Table 5).

\section{Discussion}

\section{Adherence to Antihypertensive Medications}

This cross-sectional study examined the level of medication adherence and associated factors among Syrian refugees with hypertension in Jordan. In our study, adherence to antihypertensive medication among Syrian refugees in 
Table 2 Patients' Behaviors and Knowledge of Hypertension Disease and Therapy with Intergroup Differences in ARMS Mean Scores $(n=180)$

\begin{tabular}{|c|c|c|c|}
\hline Variable & n (\%) & ARMS Mean (士SD) & P-value \\
\hline Uncontrolled high BP raises the risk of heart attack and stroke & & & 0.472 \\
\hline No/l do not know & $17(9.4 \%)$ & $15.2(3.1)$ & \\
\hline Yes & $163(90.6 \%)$ & $15.8(2.9)$ & \\
\hline HTN medication(s) can be replaced with CAM & & & 0.591 \\
\hline No & $118(65.6 \%)$ & $15.8(3.0)$ & \\
\hline Yes & $9(5.0 \%)$ & $16.4(3.2)$ & \\
\hline I do not know & $53(29.4 \%)$ & $15.5(2.6)$ & \\
\hline Buy HTN medication(s) if not available free of charge & & & 0.579 \\
\hline No & $73(40.6 \%)$ & $15.6(3.0)$ & \\
\hline Yes & $107(59.4 \%)$ & $15.8(2.9)$ & \\
\hline Stop/postpone refilling HTN medication(s) due to transportation/distance related issues & & & 0.129 \\
\hline No & 161 (89.4\%) & $15.6(2.8)$ & \\
\hline Yes & $19(10.6 \%)$ & $16.7(3.4)$ & \\
\hline Borrow/request HTN medication(s) from acquaintances, friends, or relatives if ran out of it & & & 0.111 \\
\hline No & $148(82.2 \%)$ & $15.6(2.9)$ & \\
\hline Yes & $32(17.8 \%)$ & $16.5(3.1)$ & \\
\hline Stop taking HTN medication(s) due to side effect(s) without consulting the physician & & & 0.007 \\
\hline No & $146(81.1 \%)$ & $15.4(2.7)$ & \\
\hline Yes & $34(18.9 \%)$ & I7.2 (3.5) & \\
\hline
\end{tabular}

Note: Lower ARMS scores indicate better adherence.

Abbreviations: ARMS, Adherence to Refills and Medications Scale; HTN, hypertension; SD, standard deviation; BP, blood pressure; CAM, complementary and alternative medicines.

Table 3 The Health Care System-Related Factors with Intergroup Differences in ARMS Mean Scores $(n=180)$

\begin{tabular}{|c|c|c|c|}
\hline Variable & n (\%) & $\begin{array}{c}\text { ARMS Mean } \\
\text { (士SD) }\end{array}$ & P-value \\
\hline Satisfaction with the health care services & & & 0.018 \\
\hline Satisfied & $134(74.4 \%)$ & $15.4(2.6)$ & \\
\hline Dissatisfied & $46(25.6 \%)$ & $16.8(3.6)$ & \\
\hline Adequacy of HTN consultation time & & & 0.013 \\
\hline No & $49(27.2 \%)$ & $16.7(3.3)$ & \\
\hline Yes & |31 (72.8\%) & $15.4(2.7)$ & \\
\hline The physician recommends healthy lifestyle changes (healthy diet, exercise regularly, consuming less salt) & & & 0.879 \\
\hline No & $53(29.4 \%)$ & $15.8(2.9)$ & \\
\hline Yes & $127(70.6 \%)$ & $15.7(3.0)$ & \\
\hline The physician explains HTN causes and complications & & & 0.007 \\
\hline No & $55(30.6 \%)$ & $16.6(3.1)$ & \\
\hline Yes & $125(69.4 \%)$ & $15.3(2.8)$ & \\
\hline Availability of cost-free HTN medication(s) dispensed by NGOs' Health facilities & & & 0.001 \\
\hline Always available & $132(73.3 \%)$ & $15.3(2.7)$ & \\
\hline Sometimes/Never & $48(26.7 \%)$ & $16.9(3.1)$ & \\
\hline A method to optimize adherence to HTN medication(s) & & & 0.144 \\
\hline Meeting the treating physician more often & $49(27.2 \%)$ & $15.5(2.8)$ & \\
\hline SMS reminders & $4(2.2 \%)$ & $18.5(4.3)$ & \\
\hline Home delivery of HTN medications & $127(70.6 \%)$ & $15.7(2.9)$ & \\
\hline
\end{tabular}

Note: Lower ARMS scores indicate better adherence.

Abbreviations: ARMS, Adherence to Refills and Medications Scale; HTN, hypertension; SD, standard deviation; NGOs, non-governmental organizations. 
Table 4 Self-Reported Adherence to Antihypertensive Medications Measured by Adherence to Refill and Medications Scale (ARMS)

\begin{tabular}{|l|c|}
\hline Variable & Mean (士SD)/n (\%) \\
\hline ARMS total score & $15.7( \pm 2.9)$ \\
Adherent & $41(22.8 \%)$ \\
Non-adherent & $139(77.2 \%)$ \\
\hline
\end{tabular}

Jordan was low, as only a small percentage (22.8\%) were adherent. The study showed that shorter duration of treatment ( $\leq 2$ years), illiteracy, discontinuation of antihypertensive medications due to side effects, infrequent availability of free antihypertensive medications at NGO health facilities, and dissatisfaction with health services were all significantly associated with low adherence levels. Here, the development and implementation of tailored interventions, consistent with the study's findings and adapted to the specific characteristics of this high-need population, are therefore crucial to overcome the challenges associated with achieving satisfactory levels of medication adherence.

Our study revealed a lower percentage of adherent patients compared to what was reported regionally ${ }^{19}$ and within the host country - Jordan (53.9\%) for patients with chronic conditions. ${ }^{20}$ This low percentage can be explained primarily by the vulnerabilities faced by refugees, which may exacerbate the relatively low adherence rates which are typically reported at $<50 \%$ for various groups of hypertensive patients. ${ }^{21}$ Generally, comparable estimates of adherence in Syrian hypertensive patients are sparse even before the war, and most of the available studies have inconsistencies in measuring and/or defining adherence. For example, a recent study reported a high rate of self-reported absence of medication interruptions at $72.2 \%$ among Syrian hypertensive refugees in Lebanon. However, adherence was assessed using a binary onequestion measure reflecting the occurrence of medication interruptions for two weeks or longer without a doctor's order, referring to underuse, but less so to other forms of adherence (intentional and unintentional), with less consideration of the multifaceted nature of adherence behavior. $^{8}$

\section{Factors Associated with Adherence Rates}

Illiteracy was associated with low adherence levels, similar to findings in China and Egypt. ${ }^{22,23}$ Low literacy skills are particularly prevalent among Syrians in Jordan-39\% of those who are 50 years old or more are illiterate, ${ }^{14}$ potentially undermining patients' ability to read and understand written medical prescriptions, medication instructions, or educational interventions. It is well known that utilizing health services requires the possession of a range of skills, including reading and writing, commonly referred to as "functional literacy". ${ }^{15}$ However, further research is needed to assess the role of "health literacy", as health outcomes are not only dependent on verbal or written communication but are also on the ability to understand and evaluate health-related information to make reasonable decisions regarding a person's health. ${ }^{24}$

Shorter treatment duration ( $\leq 2$ years) was a strong predictor of poorer adherence, consistent with regional and population-based global studies suggesting that adherence to antihypertensive medications varies over treatment duration and is generally lower in newly treated patients. $^{25,26}$ One explanation is that newly treated

Table 5 The Multivariate Linear Regression Analysis for Factors with Significant Association with ARMS Scores ( $\mathrm{n}=180)$

\begin{tabular}{|c|c|c|c|c|}
\hline Variable & $\begin{array}{l}\text { Unstandardized } \\
\text { Coefficient, B }\end{array}$ & $\begin{array}{l}\text { Standardized } \\
\text { Coefficient, } \beta\end{array}$ & $95 \% \mathrm{Cl}$ & p-value \\
\hline Treatment duration from initiation of therapy ( $\leq 2$ years) & 2.08 & 0.28 & $1.02-3.14$ & $<0.001$ \\
\hline Illiteracy & 1.45 & 0.23 & $0.32-2.58$ & 0.012 \\
\hline Dissatisfaction with health services & 1.16 & 0.17 & $0.17-2.16$ & 0.022 \\
\hline $\begin{array}{l}\text { Free HTN medications dispensed by NGOs' health facilities } \\
\text { are sometimes or never available }\end{array}$ & 1.07 & 0.16 & $0.15-2.00$ & 0.024 \\
\hline Discontinue the use of HTN medications due to side effects & 1.14 & 0.15 & $0.10-2.18$ & 0.032 \\
\hline
\end{tabular}

Notes: The model was adjusted for age, gender, marital status, and employment; Lower ARMS scores indicate better adherence; The adjusted $\mathrm{R}^{2}=0.226$; The $\mathrm{p}$-value of the model ANOVA $<0.00 \mathrm{I} ; \mathrm{Cl}$ is for the unstandardized coefficient.

Abbreviations: ARMS, Adherence to Refills and Medications Scale; HTN, hypertension; NGOs, non-governmental organizations; Cl, confidence interval. 
individuals may be unaware of or underestimate the longterm consequences of hypertension, while others may have concerns about the adverse effects of medications. Unexpectedly, the number of antihypertensive medications was not associated with adherence rate, contrasting existing evidence on the negative effect of complex regimens with multiple medications on adherence levels. ${ }^{7}$ In our study, this association was not evident, most likely due to the small sample size.

In our study, 2 out of 10 participants reported discontinuing their medications due to side effects, resulting in statistically significant lower adherence levels. Similar results have been reported regionally. ${ }^{27,28}$ One explanation is that patients may perceive the side effects of antihypertensive medications, particularly impaired sexual activity, headaches, and frequent urination, as a major impediment to normal life activities, leading to a conscious decision to discontinue medications. ${ }^{29}$ Another explanation is that displacement-related circumstances, such as lack of social support and fear of uncertainty, negatively influenced Syrian refugees' perceptions and strategies for dealing with the treatment side effects. Another explanation may also be related to the likely presence of gaps in the continuum of care due to displacement, which may have contributed to the creation or perpetuation of misconceptions about the side effects of antihypertensive medications. A recent comparative study in Australia showed that hypertensive Middle Eastern refugees, including Syrians, had more concerns about the side effects of hypertension treatment than migrants who had consciously left their country and were less exposed to the circumstances associated with displacement, which in turn led to significantly low adherence rates in the refugee group. ${ }^{30}$ Considering that subjective perceptions and beliefs may determine a person's health behaviours, ${ }^{31}$ it is recommended that future studies assess the impact of this factor on adherence levels among syrians in Jordan by using multidimensional scales that account for the complexity of human perceptions and beliefs. Also, it is recommended to use mixedmethods research approaches involving quantitative and qualitative methods, as the former provides valuable information on persistence but is less precise in examining perceptual aspects.

Given the diversity of factors associated with adherence and the unique challenges faced by the refugee population, two novel variables were assessed quantitatively for the first time among Syrian refugees. Sharing antihypertensive medications by requesting or borrowing from others and using CAM have previously been described in qualitative studies as adaptive mechanisms acquired by Syrian refugees in Jordan in response to limited health care. Such approaches are used to cope with the unstable availability of free medicines dispensed by NGOs' health facilities and the inability to buy when not available for free. ${ }^{5}$ However, little is known about their prevalence and impact on adherence in this population.

Although one-third of respondents agreed or were unsure about the use of CAM as a substitute for their prescribed antihypertensive medications, no statistical association was found, in contrast to other regional study results, highlighting the need for further research in this area. $^{32}$ This factor is particularly problematic when patients substitute their prescribed antihypertensive medications, with herbal remedies or alternative medicines resulting in minimal treatment efficacy due to lower adherence to the prescribed regimen. ${ }^{33}$ Although some CAM are effective in lowering blood pressure, use alone is still insufficient to control blood pressure in the long term. ${ }^{34}$

Sharing prescribed medication has been previously defined as

The lending of medicines by giving prescription medicines to someone else or borrowing of medicines by being given and using a medicine prescribed for another person. ${ }^{35}$

Comparable quantitative estimates are not available among Syrian hypertensive patients, and sharing of prescribed medications is nevertheless loosely described in the literature. Medication sharing behavior was not associated with adherence levels, most probably due to the complexity of its contribution to adherence behavior rather than being directly associated with adherence. It is undeniable that medication sharing is risky, especially with polypharmacy patients, and can lead to lower adherence due to incorrect dosage ${ }^{35}$ Thus, patients may perceive the prescribed treatment as ineffective, although the real issue is adherence to the medication regimen rather than the appropriateness of the treatment regimen itself. ${ }^{35}$ Among refugees, financial constraints, or irregular availability of medications at NGO facilities may force patients to request and use others' medications, which in turn can lead to lower adherence rates when dosages differ from those prescribed.

Thus, health care providers are advised to routinely inquire about both factors and, if possible, implement a hypertension management guideline that addresses the hazardous use of CAM and the unsafe sharing of prescribed medications. It is also recommended to build trust between the patient and the 
healthcare provider to help disclose the use of CAM and understand the purpose of sharing medications to avoid decreased adherence levels, unanticipated side effects, and to ensure safe and effective care.

Dissatisfaction with health care resulted in significantly low adherence rates, similar to diabetic Palestinian refugees in Jordan. ${ }^{36}$ One explanation can be derived from what Syrians reported on their negative experiences with the health workers and their preference for Syrian staff, and from another perspective what staff reported of an unbearable workload, sometimes predisposing them to clinical burnout. ${ }^{10}$ In turn, clinical burnout, can lead to a range of physical and psychological manifestations that can result in lower quality of care and therefore negatively impacting patients' satisfaction with the service. Overall, both the quality of the patient-provider relationship and the quality of practitioner performance are important in improving patients' adherence. Those findings should be interpreted and generalized with caution, as satisfaction with health care is a complex phenomenon that depends on patients' expectations and the characteristics of the country's health system. $^{37}$ Patients' expectations may affect their overall assessment of the health care provided if it does not meet their expectations, even if this is not clinically possible, eg a complete cure for hypertension or diabetes. The question here is whether patients demographic profile and refugee status, individualistic assessment and expectations, prior negative experiences, or to some extent the in-group favoritism (the tendency to favor members of one's group over members of other groups $)^{38}$ led to biases in the reported association between dissatisfaction and low adherence levels, rather than being merely related to service quality. Therefore, in addition to patient satisfaction, more objective measures are needed to assess the quality of care, such as the use of standardized patients to assess provider performance or the use of video and/or survey vignettes to assess medical communication and knowledge among health care providers.

The irregular availability of medications, sometimes referred to as "medication stock-out", is a serious and infrequently reported issue that can interfere with the control of hypertension. A steady supply of medications, especially for conditions controlled by long-term therapies, is critical to ensure continuity of care and avoid interruptions and/or changes in treatment regimens, which in turn can adversely affect clinical outcomes. ${ }^{39}$ Qualitative studies have previously reported this issue in Syrian hypertensive patients in Jordan, ${ }^{5,10}$ but how it affects adherence rates in this population has not yet been investigated.
This issue is largely related to the complex nature of drug procurement in humanitarian settings, as it is challenging to ensure financial sustainability for NGOs, particularly when delivering health care for high-need communities. Financial and logistical constraints are further exacerbated by COVID -19 long and short-term consequences. UNHCR reported that by the end of 2020 , only slightly more than half (57\%) of funding needs for refugees in Jordan were met, which could inevitably lead to cuts or low efficiency in the delivery of some services. ${ }^{40}$ On the other hand, some host countries, including Jordan, require NGOs' supplies to be aligned with local drug regulations, rendering the procurement highly dependent on the availability of local medicines and the regulatory system. ${ }^{41}$ NGOs in Jordan rely primarily on locally marketed medicines, while importation from international sources is limited to cases where medicines are not available locally or when there are delays in ordering. ${ }^{42}$ Few studies have examined the challenges associated with the procurement process for Syrian refugees in Jordan. One of those reported logistical constraints and poor storage conditions for medications in camps caused by frequent power outages. ${ }^{43}$ In the absence of explicit indicators of medications shortage within the pharmaceutical sector in Jordan as a supplier, ${ }^{44}$ regulatory issues such as lack of seamless communication and data sharing are thought to play a key role in the reported unstable availability of medicines.

\section{Practical Implications}

Pragmatic strategies to be used in refugee settings must be cost-effective, convenient, and tailored to the specific needs of this population. The use of financially and logistically demanding interventions is considered unsustainable in communities that strive primarily to achieve continuity of care and a steady supply of essential medications. Here, we propose the following recommendation based on the study findings:

- For educational and motivational interventions, it is recommended that visual and auditory aids be used in addition to traditional approaches (verbal and written) to achieve greater reach to individuals with limited literacy skills. Simple technology-based interventions and innovative methods could also be deployed to reinforce traditional face-to-face interventions. One promising intervention is userfriendly mobile phone apps that provide medication reminders, tracking reports, and educational content, such as the app already used at Zaatari camp to track vaccination records and dates. ${ }^{45}$ 
- Before treatment initiation, health care providers are required to discuss the goals of the treatment and prepare the patient for possible adverse effects and provide guidance on how to manage such issues. Providers are also encouraged to simplify medication instructions and inquire about treatment adherence in a nonjudgmental manner. Using such strategies will help improve patient-provider communication and subsequently help in disclosing unsafe practices, such as using CAM instead of prescribed antihypertensive medications.

- Applying a multiteam approach by actively engaging pharmacists, nurses, and family members in interventions to ensure the presence of support from other key players in shaping adherence behavior.

- Enhancing the strategic importance of drug supply chain management along with logistic system performance, as drug shortages and supply chain disruptions can lead to treatment interruptions by forcing changes in patients' medication regimens. The reported association between antihypertensive drug availability and lower adherence could be used as an important tool to inform national policymakers, representatives of NGOs and the national pharmaceutical sector, and funding bodies on how underperformance of supply chains is not only associated with negative health outcomes but can also result in higher financial costs.

\section{Limitations and Future Study}

Due to the nature of self-reported data, the results are susceptible to social desirability bias, in which patients may underreport socially undesirable behaviors, which would lead to an underestimation of suboptimal adherence. However, more than $50 \%$ of participants were non-adherents, suggesting that the effect of underestimation is small. Another limitation is the small sample size and the restriction of the sample to camps refugees and patients with active phone numbers. Overall, a more inclusive study of both urban and camp refugees that is independent of phone number ownership status might provide a better scenario for both estimating adherence levels and generalizing the results. As our results show that ARMS is a useful tool to explore and address the determinants of patient adherence among Arabic-speaking refugees in the Middle East, the psychometric properties (reliability and validity) of the Arabic version need to be further investigated in the future. More research needs to be carried out, to assess the role of coexisting chronic comorbidities, patient perception of hypertension disease and therapy, and health literacy. Finally, using more objective measures such as prescription refill rates is also suggested.

\section{Conclusion}

Suboptimal adherence to antihypertensive medications remains a substantial unmet need and represents a major opportunity for developing quality care programs to improve health outcomes in the refugee population. For Syrian refugees in Jordan, it is recommended that visual and auditory aids be included in educational interventions to better reach and engage people with limited literacy skills. This can be done through simple technology-based and/or traditional face-toface methods. Also, more should be done to strengthen the pharmaceutical supply chain at various levels, including management, logistical system, and financial sustainability, to respond quickly to changes in demand and prevent indirect negative impacts on adherence.

\section{Acknowledgment}

The authors would like to thank all the study participants.

\section{Funding}

The authors received no funding for this research.

\section{Disclosure}

The authors report no conflicts of interest in this work.

\section{References}

1. UNHCR. Syria emergency; March 2021. Available from: https://www. unhcr.org/syria-emergency.html. Accessed April 24, 2021.

2. ReliefWeb. Jordan response plan for the Syria crisis 2020-2022; July 2020. Jordan. Available from: https://reliefweb.int/report/jordan/jor dan-response-plan-syria-crisis-2020-2022. Accessed April 26, 2021.

3. UNHCR. Health. Jordan; 2021. Available from: https://help.unher.org/ jordan/en/helpful-services-unhcr/health-services-unhcr/. Accessed March 23, 2021.

4. El-Khatib Z, Scales D, Vearey J, Forsberg BC. Syrian refugees, between rocky crisis in Syria and hard inaccessibility to healthcare services in Lebanon and Jordan. Confl Health. 2013;7(1):18. doi:10.1186/1752-1505-7-18

5. McNatt ZZ, Freels PE, Chandler H, et al. "What's happening in Syria even affects the rocks": a qualitative study of the Syrian refugee experience accessing noncommunicable disease services in Jordan. Confl Health. 2019;13(1):1-16. doi:10.1186/s13031-019-0209-x

6. Doocy S, Lyles E, Roberton T, Akhu-Zaheya L, Oweis A, Burnham G. Prevalence and care-seeking for chronic diseases among Syrian refugees in Jordan. BMC Public Health. 2015;15(1):1097. doi:10.1186/ s12889-015-2429-3

7. Osterberg L, Blaschke T. Adherence to medication. $N$ Engl $J$ Med. 2005;353(5):487-497. doi:10.1056/NEJMra050100

8. Lyles E, Burnham G, Chlela L, et al. Health service utilization and adherence to medication for hypertension and diabetes among Syrian refugees and affected host communities in Lebanon. $J$ Diabetes Metab Disord. 2020;19(2):1245-1259. doi:10.1007/s40200-020-00638-6 
9. Shahin W, Kennedy GA, Cockshaw W, Stupans I. The role of refugee and migrant migration status on medication adherence: mediation through illness perceptions. PLoS One. 2020;15(1):e0227326. doi:10.1371/journal.pone. 0227326

10. Al-Rousan T, Schwabkey Z, Jirmanus L, Nelson BD. Health needs and priorities of Syrian refugees in camps and urban settings in Jordan: perspectives of refugees and health care providers. East Mediterr Heal J. 2018;24(3):243-253. doi:10.26719/2018.24.3.243

11. Akik C, Ghattas H, Mesmar S, Rabkin M, El-Sadr WM, Fouad FM. Host country responses to non-communicable diseases amongst Syrian refugees: a review. Confl Health. 2019;13(1):1-3. doi:10.1186/s13031-019-0192-2

12. ReliefWeb. Jordan: Zaatari camp dashboard (July 2021); August 2021. Jordan. Available from: https://reliefweb.int/report/jordan/jor dan-zaatari-camp-dashboard-july-2021. Accessed August 18, 2021.

13. Oxfam International. Life in Za'atari, the largest Syrian refugee camp in the world; July 2020. Available from: https://www.oxfam.org/en/lifezaatari-largest-syrian-refugee-camp-world. Accessed June 23, 2021.

14. Fafo-report. The living conditions of Syrian refugees in Jordan; 2019. Available from: https://www.fafo.no/zoo-publikasjoner/fafo-rapporter /item/the-living-conditions-of-syrian-refugees-in-jordan. Accessed March 23, 2021.

15. UNESCO Digital Library. Records of the general conference, 20th session, Paris, 24 October to 28 November 1978, v. 1: resolutions; 1979. Available from: https://unesdoc.unesco.org/ark:/48223/ pf0000114032.page=183. Accessed August 18, 2021.

16. Kripalani S, Risser J, Gatti ME, Jacobson TA. Development and evaluation of the Adherence to Refills and Medications Scale (ARMS) among low-literacy patients with chronic disease. Value Health. 2009;12(1):118-123. doi:10.1111/j.1524-4733.2008.00400.x

17. Lyles E. Care utilization and adherence to medication for hypertension and diabetes among Syrian refugees and host communities in Lebanon; October 4, 2019. Available from: https://jscholarship. library.jhu.edu/handle/1774.2/62235. Accessed August 26, 2021.

18. Zidan A, Awisu A, El-Hajj MS, Al-Abdulla SA, Figueroa DCR, Kheir N. Medication-related burden among patients with chronic disease conditions: perspectives of patients attending non-communicable disease clinics in a primary healthcare setting in Qatar. Pharmacy. 2018;6(3):85. doi:10.3390/pharmacy6030085

19. Al-Qasem A, Smith F, Clifford S. Adherence to medication among chronic patients in Middle Eastern countries: review of studies; 2011. Pubmed. Available from: https://pubmed.ncbi.nlm.nih.gov/22259896/ . Accessed April 5, 2021.

20. Basheti IA, Saqf El Hait S, Qunaibi EA, Aburuz S, Bulatova N. Associations between patient factors and medication adherence: a Jordanian experience. Pharm Pract (Granada). 2016;14(1):639. doi:10.18549/PharmPract.2016.01.639

21. Burnier M, Egan BM. Adherence in hypertension: a review of prevalence, risk factors, impact, and management. Circ Res. 2019;124 (7):1124-1140. doi:10.1161/CIRCRESAHA.118.313220

22. Shi S, Shen Z, Duan Y, Ding S, Zhong Z. Association between medication literacy and medication adherence among patients with hypertension. Front Pharmacol. 2019;10:822. doi:10.3389/ fphar.2019.00822.

23. Hussein A, Awad MS, Mahmoud HEM. Patient adherence to antihypertensive medications in upper Egypt: a cross-sectional study. Egypt Hear J. 2020;72(1):29. doi:10.1186/s43044-020-00066-0

24. Sørensen K, Van Den Broucke S, Fullam J, et al. Health literacy and public health: a systematic review and integration of definitions and models. BMC Public Health. 2012;12(1):1-13. doi:10.1186/1471-2458-12-80

25. Abu-El-Noor NI, Aljeesh YI, Bottcher B, Abu-El-Noor MK. Assessing barriers to and level of adherence to hypertension therapy among Palestinians living in the gaza strip: a chance for policy innovation. Int J Hypertens. 2020;2020:1-12. doi:10.1155/2020/7650915
26. Corrao G, Zambon A, Parodi A, et al. Discontinuation of and changes in drug therapy for hypertension among newly-treated patients: a population-based study in Italy. J Hypertens. 2008;26(4):819-824. doi:10.1097/HJH.0b013e3282f4edd7

27. Lemay J, Waheedi M, Al-Sharqawi S, Bayoud T. Medication adherence in chronic illness: do beliefs about medications play a role? Patient Prefer Adherence. 2018;12:1687-1698. doi:10.2147/PPA. S169236

28. Yassine M, Al-Hajje A, Awada S, et al. Evaluation of medication adherence in Lebanese hypertensive patients. $J$ Epidemiol Glob Health. 2016;6(3):157-167. doi:10.1016/j.jegh.2015.07.002

29. Tedla YG, Bautista LE. Drug side effect symptoms and adherence to antihypertensive medication. Am J Hypertens. 2016;29(6):772-779. doi:10.1093/ajh/hpv185

30. Shahin W, Kennedy GA, Cockshaw W, Stupans I. The role of medication beliefs on medication adherence in middle eastern refugees and migrants diagnosed with hypertension in Australia. Patient Prefer Adherence. 2020;14:2163-2173. doi:10.2147/PPA. S274323

31. Janz NK, Becker MH. The health belief model: a decade later. Heal Educ Behav. 1984;11(1):1-47. doi:10.1177/109019818401100101

32. Bader RJK, Koprulu F, Hassan NAGM, Ali AAA, Elnour AA. Facteurs prédictifs de l'adhésion aux traitements antihypertenseurs dans le nord des Émirats Arabes Unis. East Mediterr Heal J. 2015;21 (5):309-318. doi:10.26719/2015.21.5.309

33. Krousel-Wood MA, Muntner P, Joyce CJ, et al. Adverse effects of complementary and alternative medicine on Antihypertensive medication adherence: FINDINGS from the cohort study of medication adherence among older adults. $J$ Am Geriatr Soc. 2010;58(1):54-61. doi:10.1111/j.1532-5415.2009.02639.x

34. Moser M. Effective treatment of hypertension without medication: is it possible? J Clin Hypertens. 2004;6(5):219-221. doi:10.1111/ j.1524-6175.2004.02875.x

35. Goldsworthy RC, Schwartz NC, Mayhorn CB. Beyond abuse and exposure: framing the impact of prescription-medication sharing. Am J Public Health. 2008;98(6):1115-1121. doi:10.2105/AJPH.2007.123257

36. Canali G, Tittle V, Seita A. Medication adherence by Palestine refugees living in Jordan who have diabetes: a cross-sectional study. Lancet. 2018;391:S13. doi:10.1016/S0140-6736(18)30379-9

37. Manzoor F, Wei L, Hussain A, Asif M, Shah SIA. Patient satisfaction with health care services; an application of physician's behavior as a moderator. Int J Environ Res Public Health. 2019;16(18):3318. doi:10.3390/ijerph16183318

38. Everett JAC, Faber NS, Crockett M. Preferences and beliefs in ingroup favoritism. Front Behav Neurosci. 2015;9(2):15. doi:10.3389/FNBEH.2015.00015

39. World Health Organization. Medicines supply; August 2017. Available from: https://www.who.int/medicines/areas/access/sup ply/en/. Accessed March 7, 2021.

40. Org/Jo, Jordan. Operational update; 2020; December 2020. Available from: https://reliefweb.int/report/jordan/jordan-unhcr-operationalupdate-december-2020. Accessed May 5, 2021.

41. Ansbro É, Garry S, Karir V, et al. Delivering a primary-level non-communicable disease programme for Syrian refugees and the host population in Jordan: a descriptive costing study. Health Policy Plan. 2020;35(8):931-940. doi:10.1093/heapol/czaa050

42. Karir V, Bygrave H, Cepuch C, et al. Accessibility to medicines for major non-communicable diseases in Jordan-2018 (Internal briefing document) MSF internal briefing document; 2018. Available from: http://hdl.handle.net/10144/619475. Accessed March 24, 2021.

43. RAPS. Challenges providing pharmaceutical products to Syrian refugees; May 2017. Available from: https://www.raps.org/regulatoryfocus $\% \mathrm{E} 2 \% 84 \% \mathrm{~A} 2 /$ news-articles/2017/5/challenges-providing-pharma ceutical-products-to-syrian-refugees.Accessed March 24, 2021. 
44. Alefan Q, Amairi R, Tawalbeh S. Availability, prices and affordability of selected essential medicines in Jordan: a national survey 16 studies in human society 1605 policy and administration 14 economics 1402 applied economics. BMC Health Serv Res. 2018;18(1):787. doi:10.1186/s12913-018-3593-9
45. Khader YS, Laflamme L, Schmid D, et al. Children Immunization App (CIMA) among Syrian refugees in Zaatari Camp, Jordan: protocol for a cluster randomized controlled pilot trial intervention study. J Med Internet Res. 2019;21(10):1-8. doi:10.2196/13557

\section{Publish your work in this journal}

Patient Preference and Adherence is an international, peer-reviewed, open access journal that focusing on the growing importance of patient preference and adherence throughout the therapeutic continuum. Patient satisfaction, acceptability, quality of life, compliance, persistence and their role in developing new therapeutic modalities and compounds to optimize clinical outcomes for existing disease states are major areas of interest for the journal. This journal has been accepted for indexing on PubMed Central. The manuscript management system is completely online and includes a very quick and fair peer-review system, which is all easy to use. Visit http:// www.dovepress.com/testimonials.php to read real quotes from published authors. 